\title{
VARIATION OF PHOTOGRAPHIC SENSITIVITY WITH DIFFERENT LIGHT SOURCES
}

\author{
By Raymond Davis and Gerald Kent Neeland
}

\section{ABSTRACT}

The variation of photographic sensitivity (as measured by the index $10 / E_{m}$ ) with different light sources of equal visual intensity, but having different distributions of energy, was experimentally obtained. Ordinary, orthochromatic, and three new fast panchromatic plates were investigated. Distinction was made between two types of sensitivity comparisons. Thus it was found that, first, the ratio of the sensitivity of any one of the panchromatic plates to that of the ordinary plate was greater with "incandescent" lighting than when "sunlight" was used, and second, in all cases the panchromatic plates were less sensitive to "incandescent" lighting than to "sunlight." Approximate factors are included (for the particular emulsions studied) by which visual exposure meter readings should be multiplied when certain types of illuminants are encountered.

\section{CONTENTS}

I. Introduction $------1--$

II. Procedure and results.

III. Discussion of results

\section{INTRODUCTION}

The sensitivity of photographic emulsions to various light sources having different spectral energy distributions has recently become of considerable interest. This is due, in part, to the discovery of new dyes which make possible increased sensitivity to the red end of the spectrum.

Artificial illuminants, particularly incandescent lamps, have a relatively large amount of energy in the longer wave lengths. With such illumination, therefore, it is natural to expect the increase in red sensitivity to make the new emulsions more efficient than former ones, i. e., less exposure will be required to obtain the same photographic effect.

Comparisons of sensitivity may be made in one of two ways. First, one may compare the sensitivity of two different emulsions using the same source. Second, the sensitivity of an emulsion to one source may be compared with its sensitivity to another source of equal "intensity" but having a different relative spectral energy distribution. ${ }^{1}$

The question arises as to whether equal "intensity" should be taken to mean equal energy or equal visual intensity. That the two would not be necessarily the same is obvious. In certain problems, such as, for example, determining the type of illuminant which is

1 The terms "relative spectral energy distribution" and "energy distribution" have the same meaning in this paper.

$79688-31-6$ 
most efficient with a given emulsion, it is desirable to have the sources under comparison arranged to deliver to the plate the same amount of energy per unit time. With this arrangement, the source to which the emulsion has the higher sensitivity would be the most efficient; that is, a greater photographic effect is obtained with a given amount of energy.

However, in carrying out the experimental work of this paper, we have taken equal intensity to mean equal visual intensity. That this condition for sensitivity comparisons has practical significance may be seen from consideration of a "visual photometer" type of exposure meter in common use. With this instrument the exposure for two objects is indicated as being the same when the light reflected from each object appears equally bright regardless of its energy distribution. ${ }^{2}$ Therefore, to use this type of meter properly, it is necessary to know how the sensitivity of the emulsion varies with different types of illuminants.

In this paper are given several examples showing the variation in sensitivity (of panchromatic, orthochromatic, and ordinary plates) with the energy distribution of the light where the visual intensity of the light incident on the emulsion is kept constant. This information is of interest, not only with regard to the use of an exposure meter, but particularly because it furnishes actual data on the performance of new panchromatic emulsions as compared with ordinary emulsions.

\section{PROCEDURE AND RESULTS}

The emulsio studied were exposed to three sources each having a different energy distribution. These were: (1) an incandescent lamp operating at a color temperature ${ }^{3}$ of $2,360^{\circ} \mathrm{K}$.; (2) an incandescent lamp operating at a color temperature of $2,810^{\circ} \mathrm{K}$.; and (3) an incandescent lamp operating at $2,360^{\circ} \mathrm{K}$. in combination with a Davis-Gibson filter such that the resulting light closely approximates the chromaticity and the energy distribution of mean noon sunlight. ${ }^{4}$

Energy distribution curves for these three sources together with the visibility curve, $V$, are given in Figure 1.

These sources were chosen because it was desired to approximate, as far as possible with available equipment, light conditions, both out of doors in sunlight and inside with incandescent illuminants. Thus the ordinary 60-watt gas filled incandescent lamp approximates a color temperature of $2,800^{\circ} \mathrm{K}$. while the old vacuum tungsten lamp approximates a color temperature of $2,400^{\circ} \mathrm{K}$. The incandescent lamps, such as are used for studio work in motion pictures, are close to a color temperature of $3,000^{\circ} \mathrm{K}$.

The sources were placed in a nonintermittent sectorwheel sensitometer ${ }^{5}$ at such distances from the plane of the emulsion that the visual intensity at this plane was 1 meter candle.

${ }^{2}$ It is assumed here that the photometer employs no blue, or other, "correction" filter. However, the mere inclusion of such a filter would not, necessarily, correct for the different energy distributions of various sources. Thus, only with ordinary plates could reliable readings be obtained with a blue filter.

$8 \mathrm{By}$ a color temperature of $2,360^{\circ} \mathrm{K}$. is meant that the chromaticity of the light approximates that of $\mathrm{a}$ Planckian radiator at an absolute temperature of $2,360^{\circ}$. In the case of an incandescent lamp, the relative spectral energy distribution, as well as the chromaticity, is also very close to that of the Planckian radiator at the specified temperature.

1 The chromaticity of mean noon sunlight is approximately that of a Planckian radiator at $5,400^{\circ} \mathrm{K}$.

- The sensitometer used is doscribed in B. S. Sci. Pap. No. 511. 
As pointed out in a previous paper, ${ }^{6}$ we believe that the most adequate representation of the sensitivity of an emulsion is given by a curve showing the relation between sensitivity and development time. It was thought best to use the index of sensitivity $10 / E_{m}{ }^{7}$, where $E_{m}$ is the exposure value of that point in the "toe" region of the characteristic curve of the emulsion where the gradient is 0.2 .

In each test, 24 sensitometric strips, backed with a black shellac mixture to prevent halation, were exposed; 8 to each of the three sources. In several instances the tests were repeated a number of times. The 24 exposed strips were placed in eight racks, each containing three strips, one exposed to each source. The racks were then placed together in a single tray of developer which was kept at $20^{\circ} \mathrm{C}$. by a water bath. They were removed, one rack at a time, after periods giving a series of development times from 2 to 22 minutes.

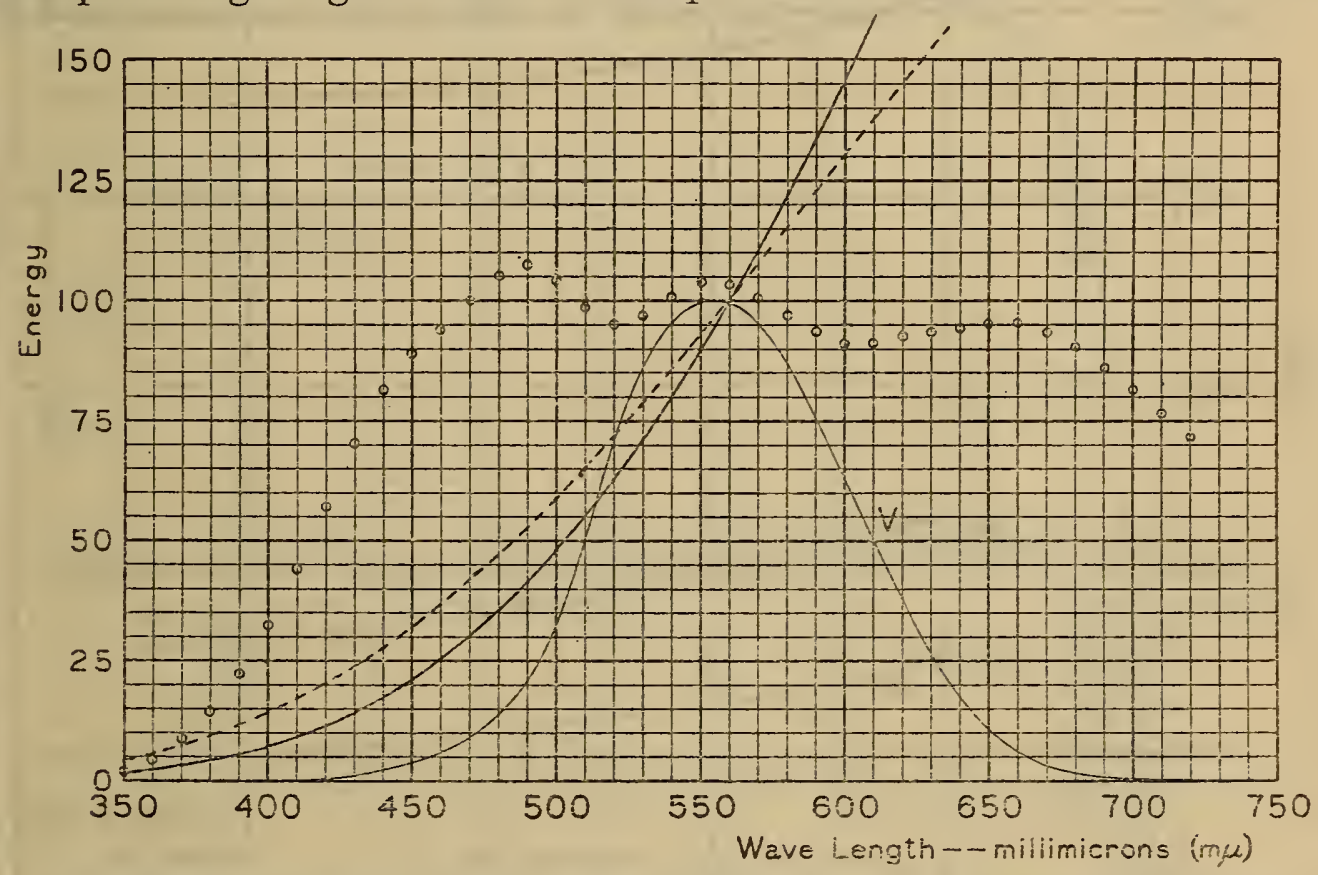

FigdRE 1.-Relative spectral energy distribution of the light sources used

The circles represent the spectral energy of the lamp and filter combination producing artificial sunlight. The Eighth International Congress of Photography adopted this as standard for the sensitometry of negative materials. The dashed line represents the spectral energy of $2,810^{\circ} \mathrm{K}$. and the solid line $2,360^{\circ} \mathrm{K}$., both arbitrarily adjusted to 100 at $\lambda 560 \mathrm{~m} \mu$. The visibility curve is marked "V."

Thus the usual range of development times was more than covered. Agitation of the developer was maintained by brushing the plates with a camel's-hair brush.

Pyrogallol-developer, compounded according to the following formula, was employed:

(A) Water

Potassium metabisulphite

Pyrogallol

(B) Water

(C) Sodium sulphite (anhydrous)

Sodium carbonate (anhydrous)

- For a discussion of several indices and methods of representing sensitivity, see the paper by Raymond Davis and $G$. K. Neeland, an experimental study of several methods of representing photographic sensitiv. ity, B. S. RP355.

7 This index was proposed by L. A. Jones in Proc. Seventh Int. Cong. of Phot., 1928, p. 130, and further discussed in the paper by the authors. (See footnote 6.) 
To develop, 1 part each of $\mathrm{A}, \mathrm{B}$, and $\mathrm{C}$ was mixed with 7 parts of water.

The densities of the developed strips were measured in diffuse light with a Martens polarization photometer. A family of eight characteristic curves (total density versus log exposure) was obtained for each source. From each curve a value of the index $10 / E_{m}$ was derived. Thus a measure of the variation of sensitivity with the time of development was obtained for each source. From these data the sensitivity versus development-time curves were drawn.

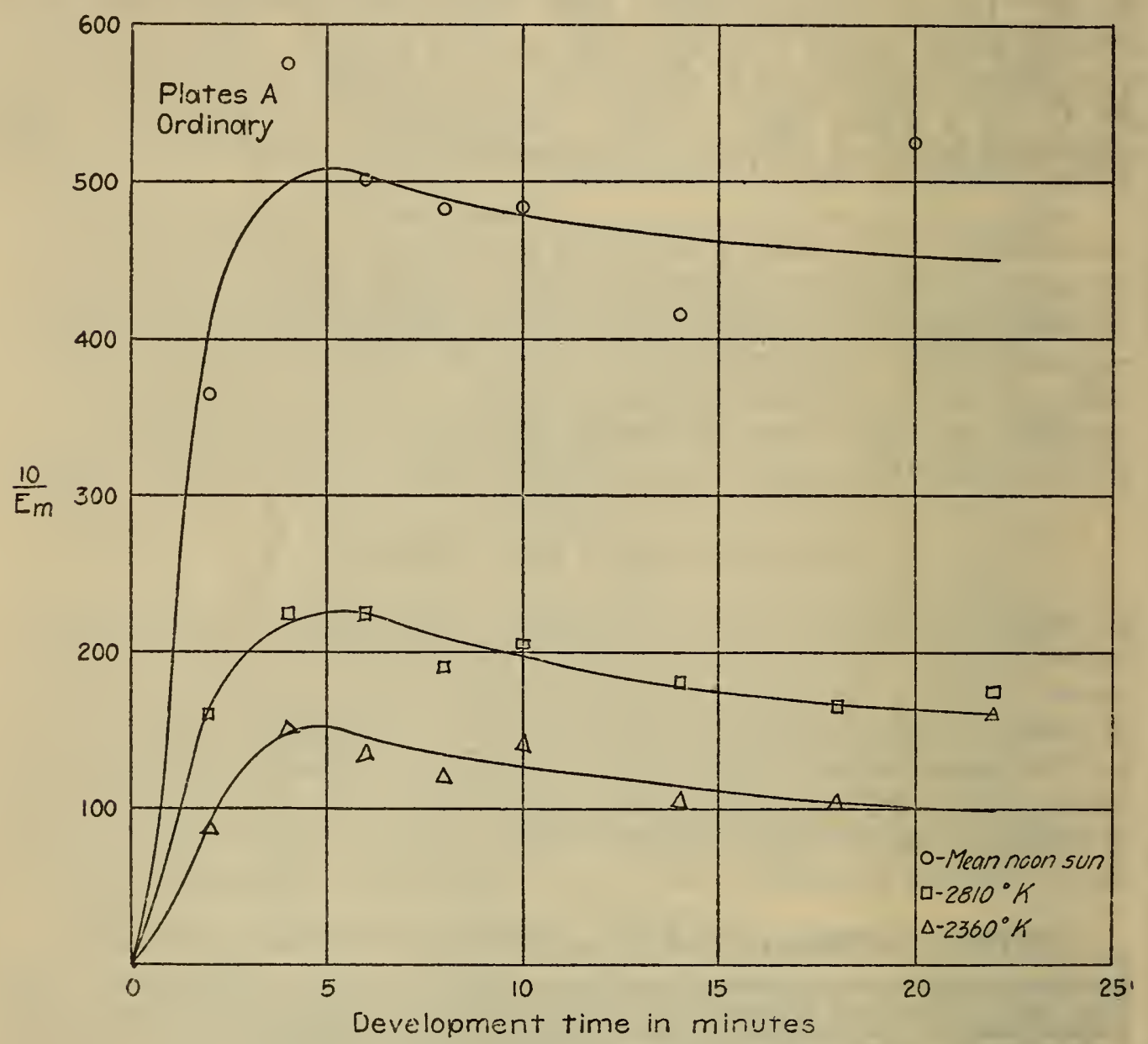

Figdre 2.-Sensitivity versus development-time curves for Plates $A$ under three conditions of illumination

In Table 1 are listed the plates included in the study, the types of emulsions, and the identifying letters used in the figures and tables. The selection is intended to be representative of the most sensitive emulsions now available, and to include an example of each of the three common types of emulsions-ordinary, orthochromatic, and panchromatic.

\section{DISCUSSION OF RESULTS}

Curves representing the change in sensitivity (as measured by the index $10 / E_{m}$ ) with the time of development for each of the three sources are given in Figures 2 to 6, inclusive.

In Figure 2 these curves are given for Plates $A$. The three curves are similar in shape, as would be expected, and show the usual ${ }^{8}$

- For a discussion of this type of curve, see the paper by the authors (footnote 6). 
optimum time of development (here 5 minutes). Since these plates are "ordinary" (not "color sensitive"), the drop in sensitivity with the lower color-temperature sources is large compared to that for the panchromatic plates.

In Figure 3, similar curves are given for Plates B. Although these plates are orthochromatic the drop in sensitivity is nearly as great as with the ordinary plates.

In Figure 4, the curves for the panchromatic plates (C) indicate a drop in sensitivity which is, for practical purposes, negligible. Although these are not as sensitive as Plates D, their sensitivity is less diminished by the "incandescent" type of illumination.

Figure 5 presents the curves for plates D, the most sensitive of the five brands studied. Even though their loss in sensitivity with "incandescent" illumination is greater than with plates $\mathrm{C}$, the plates $\mathrm{D}^{9}$ are more sensitive with all three sources.

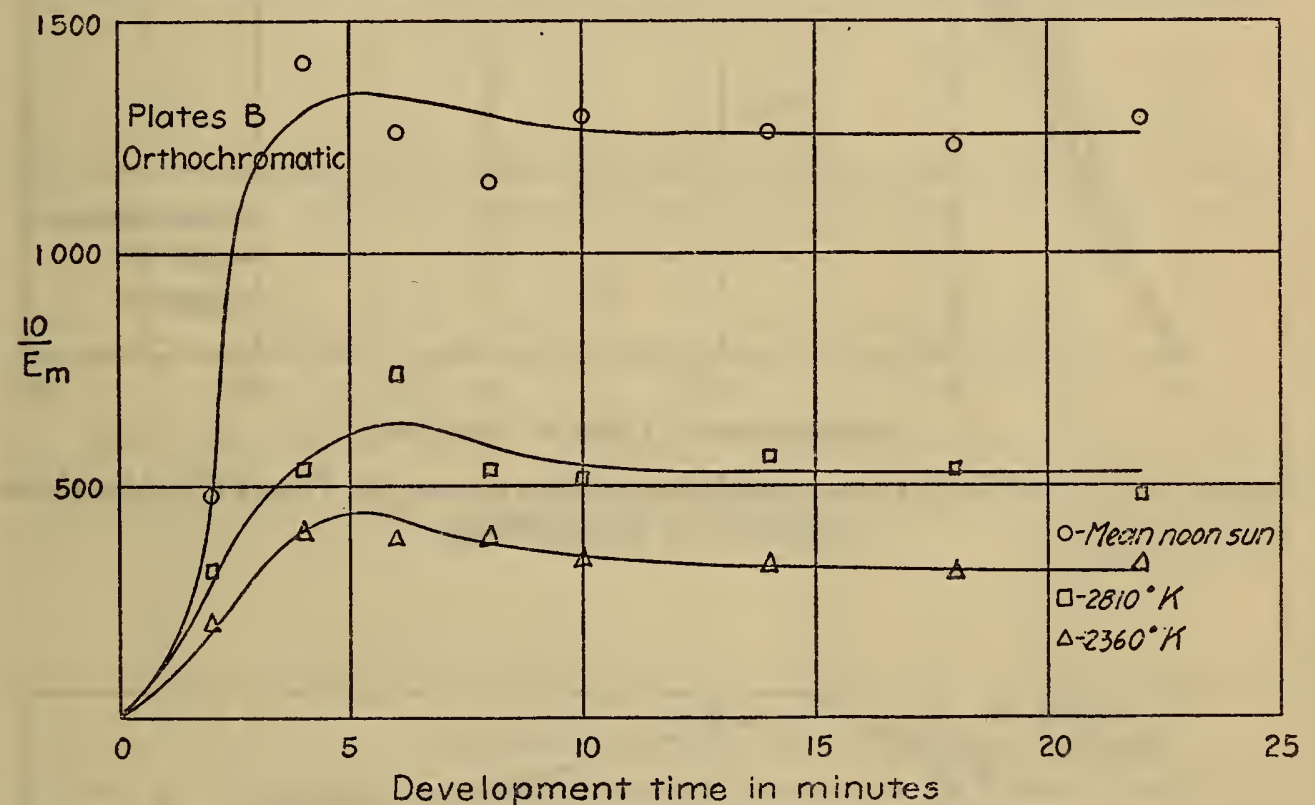

FIGURE 3.-Sensitivity versus development-time curves for Plates B under three conditions of illumination

In Figure 6, plates $\mathrm{E},{ }^{10}$ we have an example of a panchromatic plate in which the maximum sensitivity is reached at a long time of development.

Table 2 gives the data on the sensitivity (as measured by $10 / E_{m}$ ) of the five brands of plates in a more easily visualized form. To obtain these values, each sensitivity versus development-time curve is represented by its maximum value. ${ }^{11}$ The resulting number is thus more accurately representative than any of the experimentally obtained values of the index. The table shows that (1) the ratio of the sensitivity of the panchromatic to the ordinary plates is greater for "incandescent" lighting than with "sunlight," and (2) with every

- It is interesting to note here that these plates, (D), which are advertised to have a higher " $H+D$ " speed to "half-watt" light than to daylight, do not appear to justify the claim.

10 Although advertised as "special rapid," these plates are considerably slower than the other two brands of panchromatic plates.

11 The representation of the panchromatic plates $\mathbf{E}$ by a single number is not strictly comparable with the others, since the maximum value of the index occurs at a development time exceeding 22 minutes and was therefore unobtainable. 


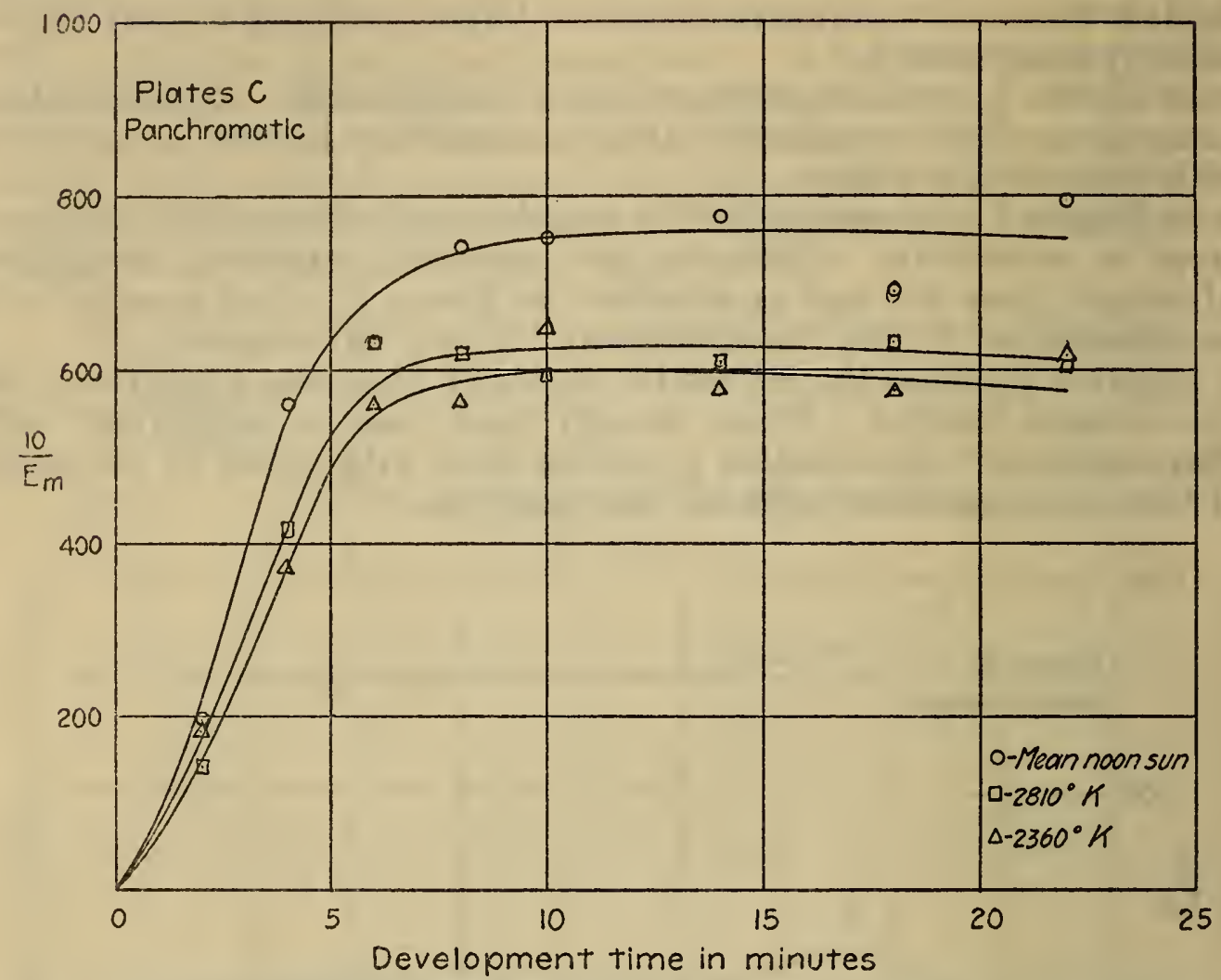

Figure 4.-Sensitivity versus development-time curves for Plates $C$ under three conditions of illumination

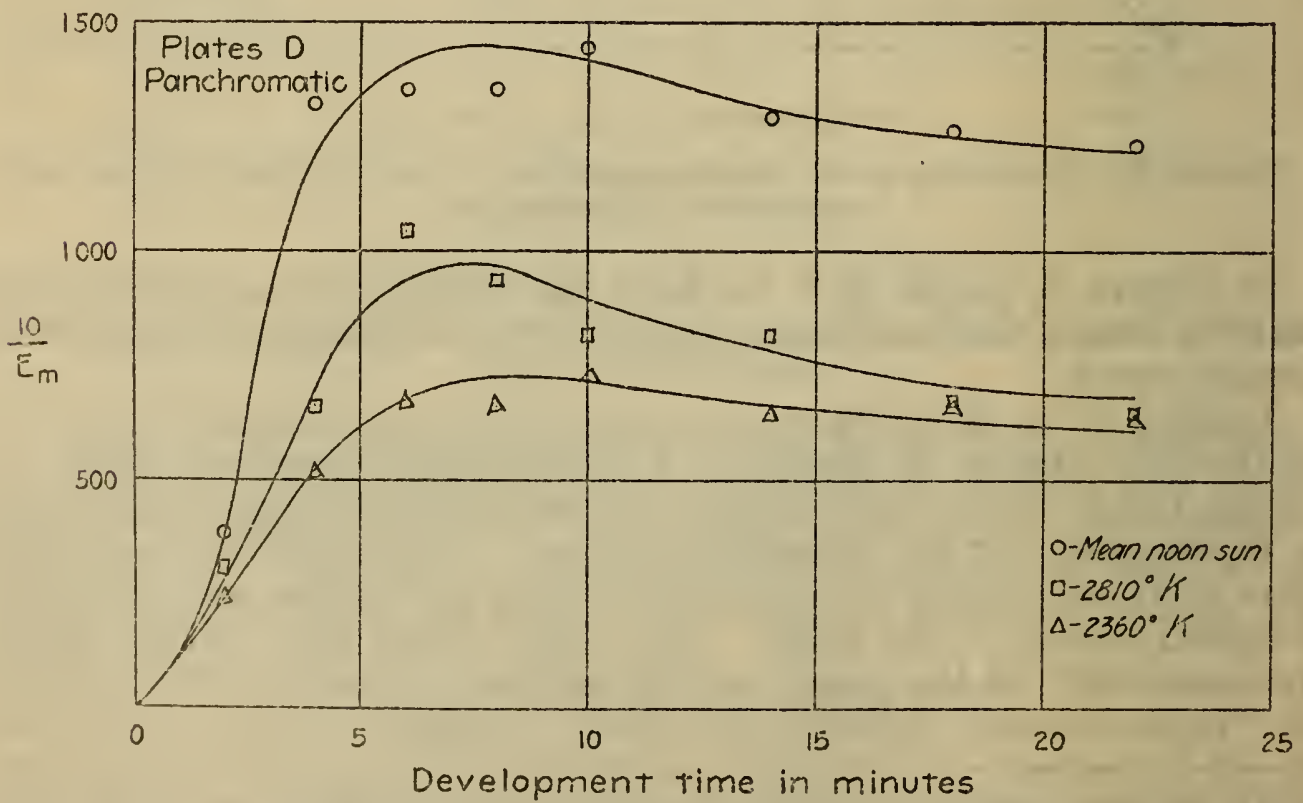

Figure 5.-Sensitivity versus development-time curves for Plates $D$ under three conditions of illumination 
brand of plate the sensitivity decreases with decreasing color temperature of the source.

The values of Table 3 were obtained from the data in Table 2. This table gives the correct exposure for a given plate to a given source, that of the ordinary plates to sunlight being taken as unity.

At present the use of the "visual photometer" type of exposure meter is fairly common. Usually with such a device provision is made for the difference in sensitivity of the several types of photographic materials. However, assuming that the correct exposure to

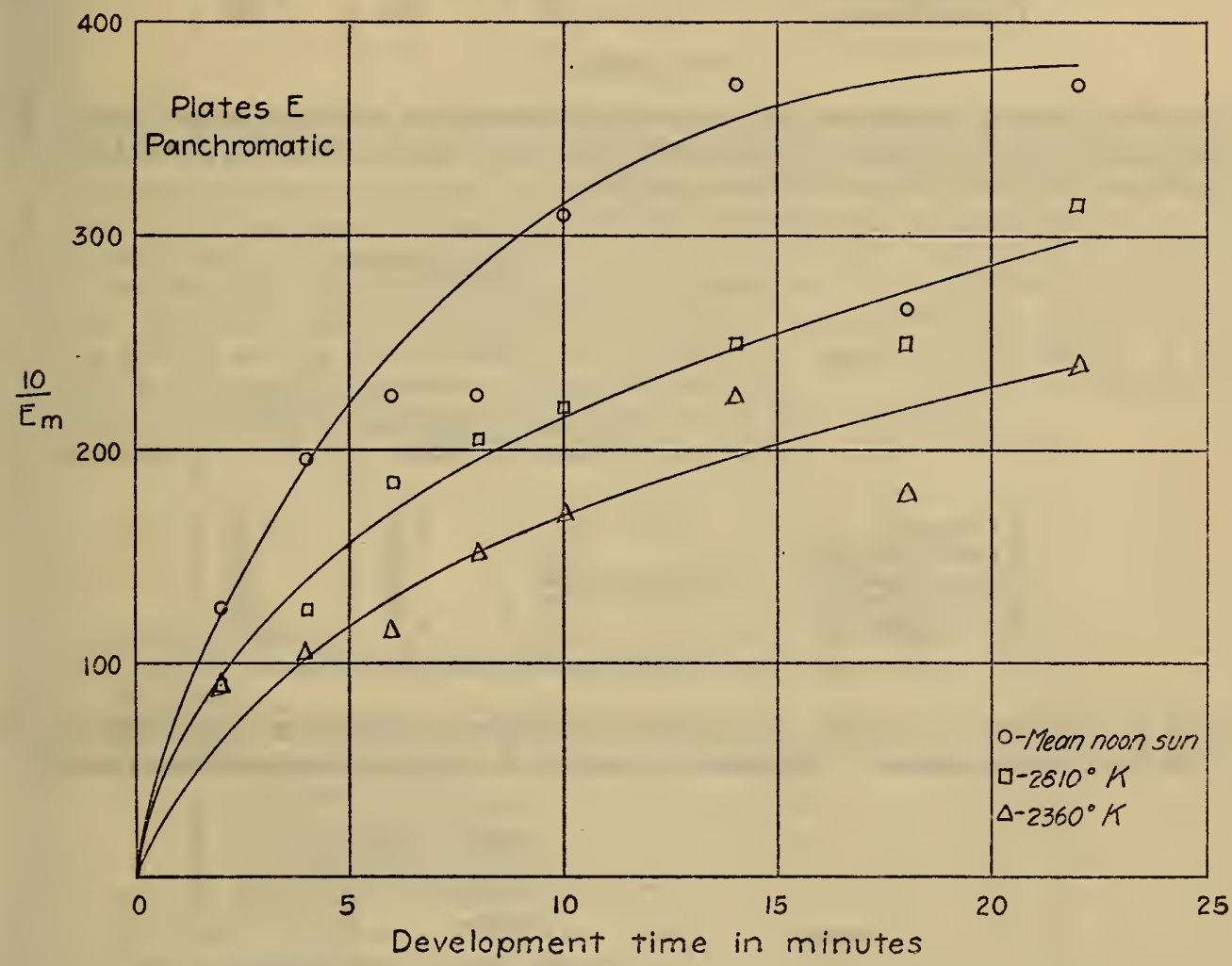

Figdre 6.-Sensitivity versus development-time curves for Plates E under three conditions of illumination

sunlight for a certain brand of plates is known, it is important to know further how the exposure should be modified when using the meter under "incandescent" lighting conditions. This information for the five brands of plates studied is supplied by Table 4 .

TABLE 1.-Photographic plates investigated

\begin{tabular}{|c|c|c|}
\hline Description of plate & $\begin{array}{l}\text { Identifi- } \\
\text { cation }\end{array}$ & Figure \\
\hline $\begin{array}{l}\text { American "medium speed" ordinary } \\
\text { American "high speed" orthochromatic.-.. } \\
\text { American "high speed" panchromatic...- } \\
\text { English "high speed" panchromatic. } \\
\text { German "high speed" panchromatic..... }\end{array}$ & $\begin{array}{l}\mathrm{A} \\
\mathrm{B} \\
\mathrm{C} \\
\mathrm{D} \\
\mathrm{E}\end{array}$ & $\begin{array}{l}2 \\
3 \\
4 \\
5 \\
6\end{array}$ \\
\hline
\end{tabular}


$\mathrm{T}_{\mathrm{ABLE}} 2 .-\mathrm{Maximum}$ values of $10 / \mathrm{E}_{m}$ taken from the sensitivity versus developmenttime curves

\begin{tabular}{|c|c|c|c|}
\hline \multirow{2}{*}{ Plate } & \multicolumn{3}{|c|}{$\begin{array}{l}\text { Maximum value of the sensitivity } \\
\text { index }\end{array}$} \\
\hline & $2360^{\circ} \mathrm{K}$. & $2810^{\circ} \mathrm{K}$. & Mean sun \\
\hline $\begin{array}{l}\text { A (ordinary) } \\
\text { B (orthochromatic) } \\
\text { C (panchromatic) } \\
\text { D (panchromatic) } \\
\text { E (panchromatic) }\end{array}$ & $\begin{array}{l}150 \\
450 \\
600 \\
725 \\
240\end{array}$ & $\begin{array}{l}225 \\
620 \\
625 \\
975 \\
300\end{array}$ & $\begin{array}{r}505 \\
1,350 \\
755 \\
1,450 \\
380\end{array}$ \\
\hline
\end{tabular}

TABLE 3.-Factors indicating the exposure necessary to obtain similar results with each of the five plates under the three conditions of illumination, that for the ordinary plates to "sunlight" being taken as unity

\begin{tabular}{|c|c|c|c|}
\hline \multirow{3}{*}{ Plate } & \multicolumn{3}{|c|}{ Exposure factor } \\
\hline & \multicolumn{2}{|c|}{ Indoors } & \multirow{2}{*}{ Sunlight } \\
\hline & $\begin{array}{l}\text { Vacuum } \\
\text { lamps }\end{array}$ & $\begin{array}{c}\text { Gas-filled } \\
\text { lamps }\end{array}$ & \\
\hline $\begin{array}{l}\text { A (ordinary) } \\
\text { B (orthochromatic) } \\
\text { C (panchromatic) } \\
\text { D (panchromatic) } \\
\text { E (panchromatic) }\end{array}$ & $\begin{array}{l}3.4 \\
1.1 \\
.84 \\
.70 \\
2.1\end{array}$ & $\begin{array}{l}2.2 \\
.81 \\
.81 \\
.52 \\
1.7\end{array}$ & $\begin{array}{l}1.0 \\
.37 \\
.67 \\
.35 \\
1.3\end{array}$ \\
\hline
\end{tabular}

TABLE 4.-Factors indicating the exposure necessary to obtain a similar result with the two "incandescent" illuminants, that with sunlight being taken as unity

\begin{tabular}{|c|c|c|c|}
\hline \multirow{3}{*}{ Plate } & \multicolumn{3}{|c|}{ Exposure factor } \\
\hline & \multicolumn{2}{|c|}{ Indoors } & \multirow{2}{*}{ Sunlight 1} \\
\hline & $\begin{array}{l}\text { Vacuum } \\
\text { lamps }\end{array}$ & $\begin{array}{c}\text { Gas-filled } \\
\text { lamps }\end{array}$ & \\
\hline $\begin{array}{l}\text { A (ordinary) } \\
\text { B (orthochromatic) } \\
\text { C (panchromatic) } \\
\text { D (panchromatic) } \\
\text { E (panchromatic) }\end{array}$ & $\begin{array}{l}3.4 \\
3.0 \\
1.3 \\
2.0 \\
1.6\end{array}$ & $\begin{array}{l}2.2 \\
2.2 \\
1.2 \\
1.5 \\
1.3\end{array}$ & $\begin{array}{l}1.0 \\
1.0 \\
1.0 \\
1.0 \\
1.0\end{array}$ \\
\hline
\end{tabular}

1 These values do not indicate that the plates are equally sensitive to sunlight.

Washington, September 25, 1931. 